\title{
Clinical Performance of Composite Using Direct and Indirect Technique
}

AIM: This study aimed to evaluate and compare clinical performance of composite in regard to colour, marginal staining, surface roughness and chipping in anterior teeth using direct and indirect technique.

MATERIAL AND METHODS: 60 anterior teeth were selected for this study and were randomly divided into 2 groups. Facial reduction of $0.75-1 \mathrm{~mm}$ was done in both groups. In Group A ( $\mathrm{n}=30)$, veneer preparation was done directly by incremental layering technique. In Group B ( $\mathrm{n}=30)$, putty impression was taken, a cast was made and composite build up was performed on the cast. The prepared veneer was placed into visible light cure chamber for uniform curing. It was then loaded with the luting cement and gently seated on labial surface. Veneers were evaluated at baseline, 3, 6 months for colour stability, marginal staining, surface roughness and chipping according to modified USPHS criteria (Ryge's criteria). Score of Alpha, Bravo and Charlie were assigned, and the results were statistically analysed using Chi square test.

RESULT: No statistical difference was found in Group A and B at o, 3, 6 months in all parameters.

CONCLUSION: Clinical performance of direct and indirect technique for composite curing was found similar in the present study.

KEYWORDS: Composite, Veneering, Curing, Direct Technique, Indirect Technique

\section{INTRODUCTION}

The main concern in esthetic dentistry today is producing a pleasing and pleasant smile. The patient's demand for a perfect smile and improved dental appearance has raised bar in the industry with regard to materials, techniques and technology. ${ }^{1}$ The use of resin composites is extensive as they can be used for both direct and indirect restoration. ${ }^{2}$ Today's composite resin system provides the dentist with a variety of enamel and dentin shades to mimic the variations of tooth opacities and translucencies, thus providing "chameleon like effect" in small restorations. ${ }^{3}$

In case of direct veneering technique, the composite resin is applied directly to the tooth structure and is contoured to achieve natural appearance. The placement is generally accomplished in a single appointment and the patient can see the results immediately. The use of resin composite has grown considerably but other problems like post operative sensitivity, difficulty in reproducing proximal contacts, contour and polymerization shrinkage may result in longevity of the restoration for just 4-8 years. ${ }^{4}$

To overcome these challenges, manufacturers over the years have developed materials and techniques for the fabrication of indirect resin composite restoration where the restoration is processed in the laboratory or chair side curing unit. These composites differ in their method of polymerization. This has led to a better control over polymerization shrinkage, improved proximal contact, good marginal adaptation, enhanced physical properties of restorative material, improved polishability, and increased hardness. ${ }^{5}$ Also the adhesive cementation of indirect veneers by means of dual cure cements, decreases the marginal gap and compensates for the unavoidable polymerization shrinkage.

But this procedure is technique sensitive and is more time consuming including lab procedures making it more expensive when compared to direct technique.

The purpose of this clinical research was to evaluate and compare clinical performance of composite in regard to colour, marginal staining, surface roughness and chipping in anterior teeth using direct and indirect technique.

\section{METHODOLOGY}

A total of 60 patients were recruited for this study. The study was explained to each individual to include the 
need for evaluations at baseline, 3 months and 6 months. Discoloured, chipped, fractured, diastemas, Class III and Class IV lesions were included for this study.

The teeth were carefully cleaned with pumice-water slurry, rinsed with water followed by colour matching with Vita shade guide.

For tooth preparation facial reduction of $0.75^{-1} \mathrm{~mm}$ was done. In case of discolouration, cervical chamfer was modified into a butt shoulder to provide more space for the restorative material. The finish line was placed without breaking interproximal contact and confined to enamel along incisal edge. Grooves were given on either mesial or distal side for easy removal of veneer.

The teeth were divided into 2 groups and cured accordingly:-

Group A: Veneers were cured directly in the mouth (direct technique)

Group B: Veneers were cured extra-orally in a visible light cure chamber (indirect technique)

\section{Group-A (Direct technique)}

The prepared tooth was etched with $37 \%$ Phosphoric acid ( 15 seconds for dentin and 30 seconds for enamel). The adhesive agent (AdperTM Single Bond 2 ( $3 \mathrm{M}$ ESPE)) was applied according to manufacture's instruction and cured. Tooth was restored with increments of composite resin (Filtex Z 350 , 3 M ESPE) and cured. After polymerization of this layer, thin coat of glycerine was applied. A thin lead pencil was used to establish the positions of transitional line angles according to the tooth planes. Final finishing and polishing was achieved by Super-Snap Rainbow finishing kit (Shofu). (Figure 1).

\section{Group-B (Indirect technique)}

After tooth preparation, putty impression was taken and a cast was made. A thin coat of separating media was applied on prepared cast. Composite (Filtex Z350, $3 \mathrm{M}$ ESPE) build up was performed on the cast and cured for 5 seconds to allow initial hardening of composite veneer. The composite veneer was removed and marginal flashes and excessive contours were removed with coarse discs. The veneer was then placed back on the preparation to ensure accuracy of fit and interproximal contacts. After that, the veneer was



Figure 1. Direct veneer technique (a): pre-operative; (b): post-operative at baseline; (c): at 3 months; (d): at 6 months

placed into visible light cure chamber and 5 cycles of 1 minute each were carried out. Sandblasting with Aluminium oxide powder was done on internal surface of veneer to improve retention. The prepared tooth was etched followed by application of bonding agent (same as that for direct veneer). The veneer was loaded with the Rely X (3M, ESPE) luting cement and gently seated and positioned and held in place with digital pressure and cured for 4os. Final finishing and polishing was achieved by Super-Snap Rainbow finishing kit (Shofu). (Figure 2).

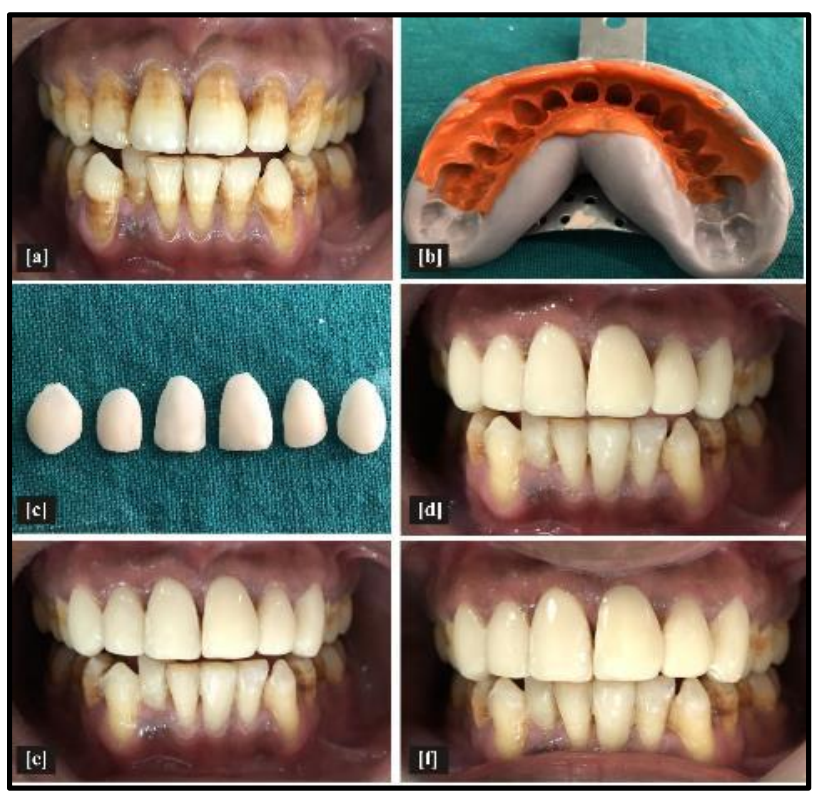

Figure 2. Indirect technique for veneer preparation (a): pre-operative; (b): putty impression; (c): prepared veneers; (d): post-operative at baseline; (e): at 3 months; (f): at 6 months 
Composite veneers were evaluated at baseline, 3 months and 6 months for colour stability, marginal staining, surface roughness and chipping with a mirror and explorer according to modified USPHS (United States Public Health Service) criteria, better known as (Ryge's criteria) and were given scores of alpha, beta and Charlie. ${ }^{6}$ The findings were then compared. Photographs were taken of each veneer at baseline and recall appointments.

\section{RESULTS}

Results were compared at baseline, 3 months and 6 months and tabulated (Table 1). The data was statistically analysed using Chi Square tests at o, 3, 6 months with $\mathrm{p}$ value $<0.05$ indicating significant differences. The results of the present study showed that the difference between Group A and Group B was statistically insignificant in terms of colour, marginal staining, surface roughness and chipping in o, 3, 6 months. Some changes were noted in both groups at the end of 6 months in terms of marginal staining. Group 2 showed $90 \%$ results at the end of 6 month as 3 out of 30 patients showed result of Bravo in the study. Group A showed 93.3\% result at end of 6 months in terms of marginal staining as 2 out of 30 patients showed Bravo score. But the Chi square test showed no statistical difference between the two. All other parameters showed result of Alpha (100\%) at the end of 3, 6 months except for 1 restoration in Group A that showed bravo score at the end of 6 months in terms of colour change. (Tables 1-3)

\section{DISCUSSION}

Aesthetic dentistry aims to give the patient the best natural looking smile, thus creating an improved and seamless transformation. It requires clinician's artistic

\begin{tabular}{|c|c|c|c|c|c|c|c|}
\hline \multirow{2}{*}{ CRITERIA } & \multirow{2}{*}{ RATIO } & \multicolumn{3}{|c|}{ GROUP A } & \multicolumn{3}{|c|}{ GROUP B } \\
\hline & & Baseline & 3 Months & 6 Months & Baseline & 3 Months & 6 Months \\
\hline \multirow{2}{*}{$\begin{array}{c}\text { SURFACE } \\
\text { ROUGHNESS }\end{array}$} & A & $100 \%$ & $100 \%$ & $100 \%$ & $100 \%$ & $100 \%$ & $100 \%$ \\
\hline & B & $100 \%$ & $100 \%$ & $100 \%$ & $100 \%$ & $100 \%$ & $100 \%$ \\
\hline \multirow[b]{2}{*}{ COLOUR } & A & $100 \%$ & $100 \%$ & $97 \%$ & $100 \%$ & $100 \%$ & $100 \%$ \\
\hline & B & $100 \%$ & $100 \%$ & $3 \%$ & $100 \%$ & $100 \%$ & $100 \%$ \\
\hline \multirow{2}{*}{$\begin{array}{l}\text { MARGINAL } \\
\text { STAINING }\end{array}$} & A & $100 \%$ & $100 \%$ & $93 \%$ & $100 \%$ & $97 \%$ & $90.0 \%$ \\
\hline & B & - & - & $6.70 \%$ & - & $3 \%$ & $10.0 \%$ \\
\hline \multirow[t]{2}{*}{ CHIPPING } & A & $100 \%$ & $100 \%$ & $100 \%$ & $100 \%$ & $100 \%$ & $100 \%$ \\
\hline & B & - & - & - & - & - & - \\
\hline
\end{tabular}

Table 1. Tabulated results at baseline (o) , 3 and 6 months of Group A (Resin cured directly), Group B (Resin cured indirectly)

\begin{tabular}{|c|c|c|c|c|c|c|c|c|c|c|}
\hline & Value & df & $\begin{array}{l}\text { Asymp. } \\
\text { Sig. (2- } \\
\text { sided) }\end{array}$ & $\begin{array}{c}\text { Exact } \\
\text { Sig. } \\
\text { (2-sided) }\end{array}$ & $\begin{array}{l}\text { Exact Sig. } \\
\text { (1-sided) }\end{array}$ & Value & df & $\begin{array}{l}\text { Asymp. Sig. } \\
\text { (2-sided) }\end{array}$ & $\begin{array}{l}\text { Exact Sig. } \\
\text { (2-sided) }\end{array}$ & $\begin{array}{l}\text { Exact Sig. } \\
\text { (1-sided) }\end{array}$ \\
\hline $\begin{array}{c}\text { Pearson Chi- } \\
\text { Square } \\
\end{array}$ & 1.017a & 1 & .313 & - & - & $.218 a$ & 1 & .640 & - & - \\
\hline $\begin{array}{l}\text { Continuity } \\
\text { Correction }\end{array}$ & .000 & 1 & 1.000 & - & - & .000 & 1 & 1.000 & - & - \\
\hline $\begin{array}{c}\text { Likelihood } \\
\text { Ratio } \\
\end{array}$ & 1.403 & 1 & .236 & - & - & .220 & 1 & .639 & - & - \\
\hline $\begin{array}{c}\text { Fisher's Exact } \\
\text { Test }\end{array}$ & - & - & - & 1.000 & .500 & - & - & - & 1.000 & .500 \\
\hline $\begin{array}{c}\text { Linear-by- } \\
\text { Linear } \\
\text { Association }\end{array}$ & 1.000 & 1 & .317 & - & - & .215 & 1 & .643 & - & - \\
\hline $\begin{array}{c}\mathbf{N} \text { of Valid } \\
\text { Cases }\end{array}$ & 60 & - & - & - & - & 60 & - & - & - & - \\
\hline
\end{tabular}




\begin{tabular}{|c|c|c|c|c|c|c|c|}
\hline & GROUP & VALUE & DF & $\begin{array}{l}\text { ASYMP. SIG. (2- } \\
\text { SIDED) }\end{array}$ & VALUE & DF & $\begin{array}{l}\text { ASYMP. SIG. } \\
\text { (2-SIDED) }\end{array}$ \\
\hline \multirow{3}{*}{ GROUP A } & Pearson Chi-Square &.$^{\mathrm{a}}$ & &.$^{a}$ &.$^{a}$ & & \\
\hline & $\begin{array}{c}\text { McNemar-Bowker } \\
\text { Test }\end{array}$ & . & . & . & . & $\cdot$ &.$^{b}$ \\
\hline & $\mathrm{N}$ of Valid Cases & 30 & & 30 & 30 & & \\
\hline \multirow{3}{*}{ GROUP B } & Pearson Chi-Square &.$^{\mathrm{a}}$ & &.$^{\mathrm{a}}$ &.$^{a}$ & & \\
\hline & $\begin{array}{c}\text { McNemar-Bowker } \\
\text { Test }\end{array}$ & . & . & . & . & · & $\mathrm{b}^{\mathrm{b}}$ \\
\hline & $\mathrm{N}$ of Valid Cases & 30 & & 30 & 30 & & \\
\hline \multirow{3}{*}{ TOTAL } & Pearson Chi-Square &.$^{\mathrm{a}}$ & &.$^{\mathrm{a}}$ &.$^{\mathrm{a}}$ & & \\
\hline & $\begin{array}{c}\text { McNemar-Bowker } \\
\text { Test }\end{array}$ & . & . & . & . & · &.$^{b}$ \\
\hline & $\mathrm{N}$ of Valid Cases & 60 & & 60 & 60 & & \\
\hline
\end{tabular}

Table 3. Chi square test for surface roughness and chipping done at 0.6 months

skills as well as thorough knowledge of the tooth anatomy including its shape, colour, function and optical properties.

To meet the requirement of the patients, keeping in mind the cost and time factor and also at the same time giving the patients the esthetics they required, we used Filtex Z35o for this study.

The main drawback of composite i.e. polymerization shrinkage could be reduced with indirect curing as it involved uniform heat and light application. For indirect curing, halogen bulb and LED bulb were incorporated in a visible light cure chamber and the resin was cured in the chamber for 5 minutes. Bata Cam Yaman reported that in halogen lamps, upto $70 \%$ of the input power is converted to heat with only $10 \%$ resulting in visible light. Hence adequate heat (from halogen) and blue light (from LED) was available for indirect curing. ${ }^{7}$

Based on the present methodology, colour was evaluated using Vita classic shade guide (overhead lights turned off). The results in the present study showed no statistical difference in colour between composite cured directly or indirectly $(\mathrm{P}>0.05)$ and infact showed alpha score at baseline, 3 and 6 months (Table 2). However only 1 out of 30 patients in Group A showed score of Bravo at 6 months but the result was insignificant.
Filtex Z350 contains monomers like Bis-GMA, BisEMA, UDMA and a small portion TEGDMA which is a hydrophilic monomer. The presence of low TEGDMA in $Z_{350}$, limits the uptake of water and also decreases colour variations induced by the absorption of the staining solution, thus contributing to colour stability. Also, the filler content has a major role in composite colour stability. It has been seen that a smaller filler size results in decreased staining and enhanced esthetics. ${ }^{8}$ On the contrary, Mohmood khosravi's study reflected that all composite resins when immersed in different mouthrinses, showed acceptable colour changes. But Filtek $Z_{350}$ showed less colour change when compared to Filtek Z250. ${ }^{9}$

The surface texture of composites has a major influence on wear, plaque accumulation, discolouration and aesthetic appearance of both direct and indirect restorations. A change of $0.3 \mu \mathrm{m}$ can be felt by the patient using the tip of his tongue. A properly finished and polished restoration demonstrates enamel like gloss and texture. ${ }^{10}$

In this study, both the groups showed no surface roughness at baseline, 3 months and 6 months when checked visually with explorer and received Alpha scores. No statistical difference was seen $(\mathrm{P}<0.05)$ (Table 3). This may be attributed to smaller filler particle size of Filtex Z350 which does not create a rough surface. The results are in accordance with Lu et 
al. who reported better surface roughness of nanocomposites. In addition to the composite used, a good abrasive system should also be used. Super snap aluminum oxide polishing kits provide smooth surface as it does not displace the composite fillers. The malleability of disc promotes a homogenous abrasion of resin matrix and fillers. A study conducted by Rochna Rai et al in 2013 showed that Filtex Z350 showed least surface roughness and super snap exhibited less surface roughness than Sof-Lex."

Marginal discolouration usually is a result of defects present between composite and cavity margins. According to this study, at 3 months all restorations in Group 1 showed Alpha score, whereas 1 restoration in Group 2 showed Bravo score.

But at the end of 6 months, 2 restorations in Group 1 received Bravo score and 3 restorations in group 2 received Bravo score. The result was statistically insignificant $(\mathrm{P}>0.05)$ (Table 2).

Inadequate polymerization could be the reason for marginal discolouration in directly cured composites. The reason for marginal discolouration in composite cured indirectly could be the presence of unpolished luting cement at the veneer tooth interface. Feilzer et al. proposed that $\mathrm{C}$-factor in these thin cement layers is quite large and the contraction is equal to the polymerization shrinkage occurring in directly cured composites. $^{12}$ These discolourations were possibly at the interface of resin cement and composite or associated to adhesive layer. Slight discoloured margins are generally analogous with marginal leakage or secondary caries. However no recurrent caries or changes in pulp sensitivity were noted at 6 months. ${ }^{13}$

The last parameter that was compared was chipping which included debonding or fracture of the restoration. Group 1 and Group 2 showed $100 \%$ Alpha scores at the end of 3, 6 months, the results being statistically insignificant (Table 3). It has been seen that bevelled direct and indirect composite restorations have higher fracture resistance to fracture than non-bevelled restorations. Pradeep K Poojary in 2013 suggested that bevelling significantly decreased chances of fracture of restoration and also reduced the impact of aging on restoration quality. ${ }^{14}$

In 2011, a retrospective study was published by Flavio Renato Reis de Moura et al. where they evaluated clinical performance and reason for failure of anterior and posterior composite restorations. He found that the main reason for failure of all types of restoration is limited adhesiveness and lack of experience of the operator. ${ }^{15}$ In this study, 3M ESPE Adper TM single bond 2 adhesive was used. Polyalkenoic acid is present in almost all bonding agents manufactured by $3 \mathrm{M}$ which helps in stress dissipation. $3 \mathrm{M}$ ESPE Laboratory testing data shows that Adper provides dentin bond strength of upto $45 \mathrm{MPa}$ and enamel bond strength of upto 25 Mpa. These factors might support why our restorations didn't chip or fracture in due course of time.

\section{CONCLUSION}

Thus, it may be concluded that the clinical performance of both the direct and indirect technique for composite curing was found to be similar in the present study. To the best of our knowledge, this is the first study which compared direct and indirect technique in anteriors. However, further studies may still be planned with a larger sample size and comparison of characteristics of direct and indirect composites at increased time intervals to validate the findings of present study.

\section{REFERENCES}

1. Knezović D, Zlatarić D, Illeš IŽ, Alajbeg M, Žagar. In Vivo Evaluations of Inter-Observer Reliability Using VITA Easyshade ${ }^{\circledast}$ Advance 4.0 Dental Shade-Matching Device. Acta Stomatol Croat. 2016;50(1):34-9.

2. D'Arcangelo C, Zarow M, De Angelis F, Vadini M, Paolantonio M, Giannoni M, D'Amario M. Five-year retrospective clinical study of indirect composite restorations luted with a light-cured composite in posterior teeth. Clin Oral Investig. 2014;18(2): 615-24. 3. Ryan EA, Tam LE, Dorothy McComb. Comparative Translucency of Esthetic Composite Resin Restorative Materials. J Can Dent Assoc 2010;76:a84.

4. Mendonça JS, Neto RG, Santiago SL, Lauris JR, Navarro MF, de Carvalho RM. Direct resin composite restorations versus indirect composite inlays: one-year results. J Contemp Dent Pract. 2010;11(3):25-32.

5. Mendonca JS, Gianordoli R, Santiago SL, Lauris JRP. Two year clinical evaluation of resin composite in posterior teeth: A randomized controlled study. . The Journal of conservative Dentistry, 2016; 19(4):306-10. 6. Barnes DM, Blank LW, Gingell JC, Gilner PP. A clinical evaluation of a resin-modified glass ionomer restorative material. JADA 1995: 126(9):1245-53.

7. Yaman BC, Efes BG, Dörter C, Gömeç Y, Erdilek D, Büyükgökçesu $\mathrm{S}$. The effects of halogen and lightemitting diode light curing on the depth of cure and 
surface microhardness of composite resins. J Conserv Dent. 2011;14(2):136-9.

8. Fontes ST, María Raquel Fernández, Claudia Modena de Moura, and Sônia Saeger Meireles. Colour Stability of a Nanofill Composite: effect of different Immersion Media J Appl Oral Sci. 2009 Oct; 17(5):388391.

9. Khosravi M, Esmaeili B, Nikzad F, Khafri S. Colour Stability of Nanofilled and Microhybrid Resin-Based Composites Following Exposure to Chlorhexidine Mouthrinses: An In Vitro Study. J Dent (Tehran). 2016; 13(2):116-25.

10. Ergücü Z, Türkün LS. Surface roughness of novel resin composites polished with one-step systems. Oper Dent. 2007;32(2):185-92.

11. Rai R, Gupta R. In vitro evaluation of the effect of two finishing and polishing systems on four esthetic restorative materials. J Conserv Dent 2013;16: 564-7.
12. Feilzer AJ, De Gee AJ, Davidson CL. Setting stress in composite resin in relation to configuration of the restoration. J Dent Res. 1987;66(11):1636-9.

13. Poojary PK, Bhandary S, Srinivasan R, Nasreen F, Pramod J, Mahesh M. Influence of restorative technique, Bevelling and aging on composite bonding to sectioned incisal edges: A comparative in vitro study. J Conserv Dent. 2013 Jan; 16(1):28-31.

14. Poojary PK, Bhandary S, Srinivasan R, Nasreen F, Pramod J, Mahesh M. Influence of restorative technique, Bevelling and aging on composite bonding to sectioned incisal edges: A comparative in vitro study. J Conserv Dent. 2013;16(1):28-31.

15. de Moura FRR, Romano AR, Guerra R, Piva E, Fernando F. Three-Year Clinical Performance of Composite Restorations Placed by Undergraduate Dental Students. Braz Dent J 2011;22(2):111-6.

\section{AUTHOR AFFILIATIONS:}

1. Professor \& Head, Department of Conservative Dentistry and Endodontics, Bhojia Dental College and Hospital, Bhud, Baddi (Himachal Pradesh)

(Corresponding Author)

2. Post Graduate Student, Department of Conservative Dentistry and Endodontics, Bhojia Dental College and Hospital, Bhud, Baddi (Himachal Pradesh)

3. Professor \& Former Principal, Department of Conservative Dentistry and Endodontics, Bhojia Dental College and Hospital, Bhud, Baddi (Himachal Pradesh)

4. Associate Professor, Dr. Harvansh Singh Judge Institute of Dental Sciences and Hospital, Chandigarh

5. Senior Lecturer, Senior Lecturer, Department of Conservative Dentistry and Endodontics, Bhojia Dental College and Hospital, Bhud, Baddi (Himachal Pradesh) 6. Consultant Periodontist, Manjeet Saini Hospital, Jalandhar(Punjab) 